Ger J Exerc Sport Res 2020 · 50:453-462 https://doi.org/10.1007/s12662-020-00677-4 Received: 13 March 2020

Accepted: 5 September 2020

Published online: 6 October 2020

(c) The Author(s) 2020

\author{
Ilka Staub ${ }^{1}$ (D) $\cdot$ Robert K. Stallman ${ }^{2} \cdot$ Tobias Vogt $^{1,3}$ \\ 'Institute of Professional Sport Education and Sport Qualifications, German Sport University Cologne, \\ Cologne, Germany \\ ${ }^{2}$ Norwegian School of Sport Science (Emeritus), Oslo, Norway \\ ${ }^{3}$ Faculty of Sport Sciences, Waseda University, Tokyo, Japan
}

\title{
The relative age effect in German 11- to 18-year-old male and female swimmers
}

\section{Introduction}

The prediction of future world class athletes is very complex and has therefore been almost impossible until today. Multiple direct (primary) and indirect (secondary) influential factors impact or facilitate successful pathways of athletes (Baker \& Horton, 2004). The relative age effect (RAE) appears to be a consistent, pervasive secondary factor influencing outcome of success (Wattie, Schorer, \& Baker, 2015). Where the distribution of births in common settings like the school system is equally spread, in the sport setting there appears to be a general gradient of about $40 \%$ for athletes born in the first three months after a certain cut-off date, $30 \%$ for the second quarter, $20 \%$ for the third quarter and only $10 \%$ for the fourth quartile (Helsen, 2018).

Researchers have conceded the prevalence of a RAE across a multitude of sports (Cobley, Baker, Wattie, \& McKenna, 2009; Musch \& Grodin, 2001). The effect has shown to be predominant in male team sports (Barnsley, Thompson, \& Legault, 1992; Schorer, Cobley, Büsch, Bräutigam, \& Baker, 2009; Till et al., 2010) as well as physically demanding individual sports (Baker, Janning, Wong, Cobley, \& Schorer, 2014; Edgar \& O’Donoghue, 2005; Romann \& Cobley, 2015). However, no RAE was found in

\section{Data availability statement}

The data that support the findings of this study are available from the corresponding author, ISt, upon reasonable request. sports with more emphasis on technical skills and categorisation in weight classes (Côté, Macdonald, Baker, \& Abernethy, 2006), such as taekwondo (Albuquerque et al., 2012), judo (Albuquerque et al., 2013), basketball (Daniel \& Janssen, 1987), gymnastics (BaxterJones, Helms, Maffulli, Baines-Preece, \& Preece, 1995) and American football (Daniel \& Janssen, 1987; Stanaway \& Hines, 1995). In swimming the RAE was shown to be highly prevalent and with a transient effect over time (Cobley et al., 2017; Ferreira, Coelho, de Morais, Werneck, Tucher, \& Lisboa, 2017; Hancock, Starkes, \& Ste-Marie, 2015; Schorer et al., 2009).

It is suggested that a mixture of physical, cognitive, emotional, and motivational causes work together producing the RAE (Musch \& Grodin, 2001). Furthermore, up to one-year difference by chronological age and potentially greater biological age differences are found during the years of rapid maturation. The concept of "sport giftedness" seems to be partly grounded in the perception of physical and physiological capacities (greater height, weight, power, speed, etc.) resulting from greater maturation, being associated with chronologically older participants, regardless of whether coaches and scouts believe that talent is predominantly the result of inherent abilities and acquirable skill (Furley \& Memmert, 2016; Lemez, Baker, Horton, Wattie, \&Weir, 2014; Pearson, Naughton, \& Torode, 2006). This phenomenon is called the maturation-selection hypothe- sis. It is one of the individual constraints in connection with the concept of the RAE (Baker, Cobley, Montelpare, Wattie, \& Faught, 2010; Raschner, Müller, \& Hildebrandt, 2012; Sherar, Baxter-Jones, Faulkner, \& Russell, 2007). Differences in psychological variables are also related to chronological age, showing differences up to one year (Musch \& Grodin, 2001; Sherar et al., 2007).

Research on different levels of performance as well as comparisons of the past decades underline the role of selection in the context of long-term athlete development. These selection processes may be likely to errors because chronically older athletes may seem to be more gifted only because they are more mature than their younger counterparts. It has been shown a significant difference of pervasiveness between competitive and recreational tiers of participation, where selection processes have less influence (Cobley et al., 2009; Hancock, Ste-Marie, \& Young, 2013; Schorer et al., 2009; Till et al., 2010). In a historical perspective the magnitude of the RAE has increased. This has been shown in German as well as Brazilian soccer players. It can be assumed that the influence of selection processes due to increasing popularity over time (Cobley, Schorer, \& Baker, 2008; Costa, Albuquerque, \& Garganta, 2012). Relatively older athletes, as a consequence, have an increased probability of being selected and subsequently exposed to a higher level of coaching, training and other talent-promoting factors (Baker \& Logan, 2007; Cobley et al., 


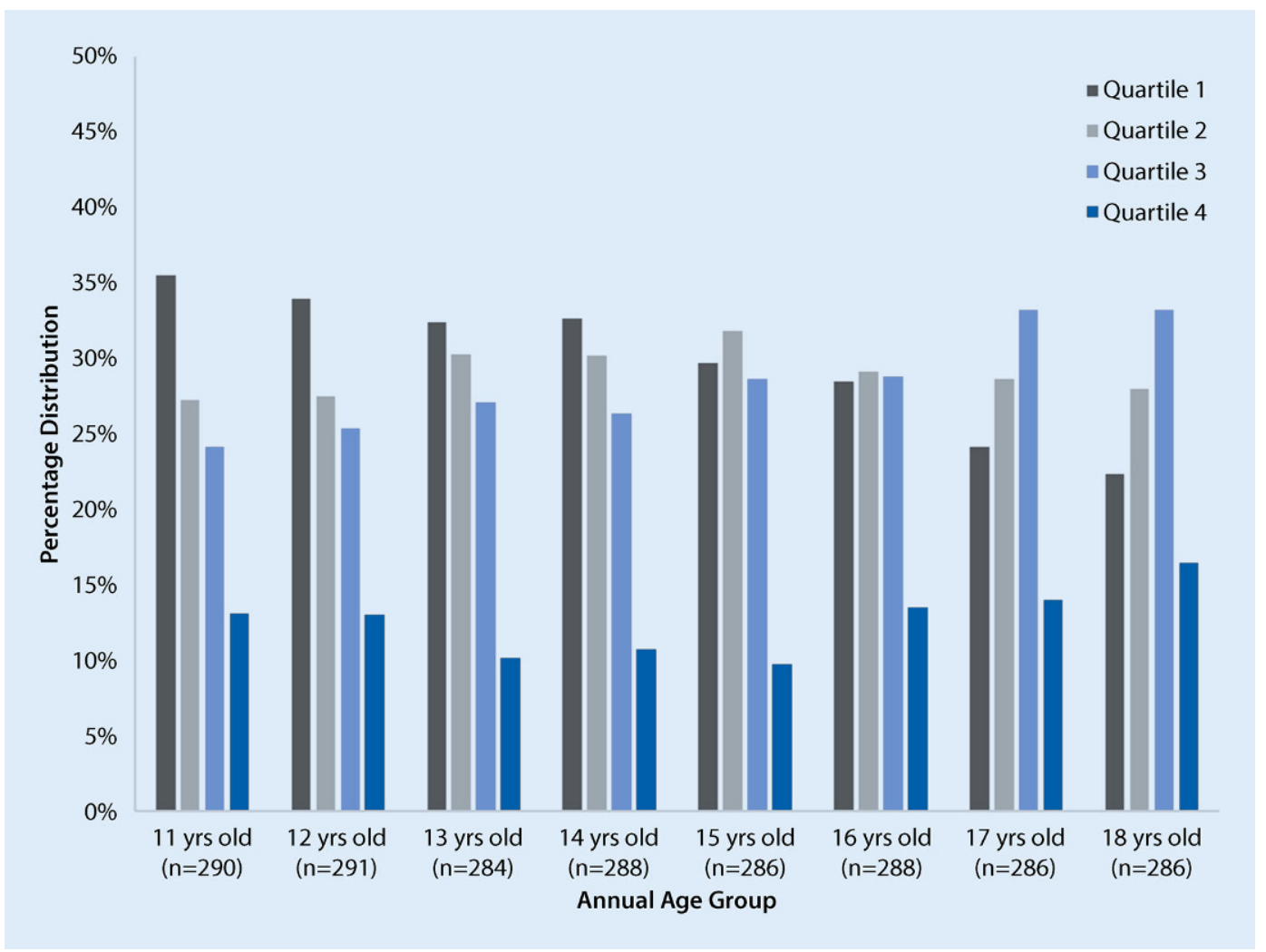

Fig. $1<$ Distribution of male swimmers listed in national top-100 rankings in $100 \mathrm{~m}$ Fly between 2004 and 2013 according to age-group and quartile. $y r s$ years
2009; Delorme, Boiché, \& Raspaud, 2010; Wattie et al., 2015).

There are a few indications of a higher likelihood of dropping out for late-born athletes in male ice-hockey (Lemez et al., 2014) and female artistic as well as individual sports (Wattie et al., 2014). In contrast to that other research reported that the RAE is persistent through adolescence and there are indications of a transience effect over time, as shown in swimming at the adult elite level (Cobley et al., 2017; Ferreira et al., 2017). The proportion of late-born children seems to balance out in some sports, including swimming. There are indications that relatively younger athletes have more continuous careers and, somehow, benefit by more competitive play with their older counterparts. This is called the 'underdog' hypothesis (Gibbs, Jarvis, \& Dufur, 2012).

Grouping by chronological age is, therefore, considered to be one of the weaknesses in the process of talent identification (Wattie \& Baker, 2017). Although the problem has been known for over 20 years, a solution still seems to be lacking. Therefore, this study aims to provide recent data in the individual sport of swimming. Furthermore, data for female athletes are still rare. This investigation aims to quantify the prevalence, magnitude and transient pattern of RAE across a German cohort of agegroup swimmers according to sex and events.

\section{Materials and methods}

\section{Samples and data preparation}

Annual age groupings are commonly broken down into quartiles when dealing with the relative age effect (RAE; Cobley et al., 2009; first meta-analytical review). The cut-off date for age-grouping in Germany is the 31st of December. For this investigation annual top-100 age group rankings (long course) for the years 2004-2013 were used. Repeated years of cross-sectional data were used to increase the number of athletes and set a representative sample of participants. Annual top100 rankings (names, events, times) were obtained from the data base of the German Swimming Federation (Deutscher Schwimm-Verband e. V. [DSV]). In total, a dataset of 62,400 samples was analyzed.
Within these rankings 3630 unique age group swimmers (male $n=1765$, female $n=1865$ ) representing the cohorts born in 1993, 1994 and 1995 between the ages 11-18 were examined. Following institutional ethical approval, the DSV provided additionally birth months of each swimmer in the dataset. The dataset was screened systematically for doubles. Multiple cases of persons that have the same name where identified and marked as different. According to a previous study (Cobley et al., 2017) the dataset contained swimmer's month of birth, sex, year of ranking, age-group, swimming stroke and distance (event). In this investigation data covered events considering stroke and within stroke factors.

\section{Procedures}

The pattern of birth quartiles was compared to actual distribution of births in the German population in the years 1993, 1994 and 1995 to judge prevalence, magnitude and transience of the RAE and to confirm that they were not associated with broader population birth patterns. Birth data were accessed from the 
German Bureau of Statistics ([DSTATIS], 2019). Across the years of births of the observed cohort, 2,333,271 live births occurred and were evenly distributed (i.e., quarter 1 [Q1]: Jan-Mar=24.8\%; Q2: Apr-Jun $=24.8 \%$; Q3: Jul-Sep $=26.5 \%$; Q4: Oct-Dec $=23.9 \%$ ). The study was conducted in consultation with the local ethics committee.

\section{Statistical analysis}

Descriptive data calculated for the samples included frequency distribution, relative frequencies (\%), mean value and standard deviation $(M \pm S D)$.

Prevalence, magnitude and transience of the RAE were determined using $\mathrm{X}^{2}$ tests. Post hoc tests, using Cramer's V estimated the magnitude of effect size between Q1 and Q4 frequency counts. Magnitude estimates ranging between $0.06<\mathrm{V}<0.17$ indicated a small effect size, $0.17<\mathrm{V}<0.29$ a medium effect, and, $V \geq 0.29$ a large effect size (Cramér, 1999).

Odds ratios (OR) and 95\% confidence intervals (CI) examined relative quartile discrepancies (i.e., Q1 vs. Q4; Q2 vs. Q4; Q3 vs. Q4). These steps were applied across age groups and according to sex and event.

Analyses were performed using SPSS version 25 (IBM, Amarok, NY, USA).

\section{Results}

- Table 1 presents relative age (quartile) distributions, $\mathrm{X}^{2}$, effect size estimation and categorization, as well as odds ratio analyses for male swimmers, ranked in the top-100 lists between 11 and 18 years of age. The relative age effect (RAE) was prevalent for both Breaststroke events (50 and $200 \mathrm{~m}$ ) between 11 and 16 years of age, $50 \mathrm{~m}$ Freestyle, $200 \mathrm{~m}$ Individual Medley as well as $100 \mathrm{~m}$ Fly between 11 and 17 years of age. In the longest of all events, $400 \mathrm{~m}$ Freestyle the unequal birth distribution was significant from 11 until 18 years of age. The RAE remains, but with reduced effect sizes in all events until $17 / 18$, after which it dissipates. Relatively older athletes (born in the first and second quartile) were up to 5.9 times more likely to be among the top-100 in the respective events (i.e., $50 \mathrm{~m}$ Freestyle, age 13-Q1 vs. $\mathrm{Q} 4=5.928$, range $=3.33-10.56$ ).

- Figures 1 and 2 visualize the summary for RAEs transiency across agegroups in male $100 \mathrm{~m}$ Fly and $200 \mathrm{~m}$ Individual Medley. The $100 \mathrm{~m}$ Fly was chosen because the stroke of Butterfly requires a high resistance to strength endurance load requirement and, therefore, involves a high level of training at a young age. Individual Medley is an event which contains of all four strokes and hence should be swum frequently in the sense of the multisport approach (Staub, Zinner, Bieder, \& Vogt, 2020a).

- Table 2 presents relative age (quartile) distributions, $\mathrm{X}^{2}$, effect size estimation and categorization, as well as odds ratio analyses for female swimmers, ranked in the top-100 lists between 11 and 18 years of age. The RAE was prevalent for $50 \mathrm{~m}$ Freestyle and $200 \mathrm{~m}$ Breaststroke between 11 and 13 years of age, for $50 \mathrm{~m}$ Breaststroke and $400 \mathrm{~m}$ Freestyle between 11 and 14 years of age. The RAE was still significant, but with a small effect in $200 \mathrm{~m}$ Breaststroke at age 13 years of age. The $200 \mathrm{~m}$ Individual Medley and 100 Fly the unequal birth distribution were significant between 11 and 15 years of age. The effect sizes reduced in all events until 14/15, after which it dissipates. Highest odds ratio showed a 5.3 times overrepresentation in favor of quartile 1 compared to quartile 4 for 12-year-olds in $50 \mathrm{~m}$ Freestyle (Q1 vs. $\mathrm{Q} 4=5.302$, range $=3.07-9.18$ ).

\section{Discussion}

The purpose of this study was to quantify the prevalence, magnitude and transience pattern of the relative age effect (RAE) across a German cohort of age-group swimmers according to sex and events. The study presents a new dataset and confirms the prevalence of RAE in swimming. RAE was visible in our investigations among male swimmers until 16/18 and female swimmers until 13-15 years of age. The magnitude of RAE decreases in the older age-groups, and the uneven distribution disappeared afterwards. There was no inverted effect in the observed data verifiable. With a closer examination of the swimming
Ger J Exerc Sport Res 2020 · 50:453-462 https://doi.org/10.1007/s12662-020-00677-4 (c) The Author(s) 2020

\section{Staub $\cdot$ R. K. Stallman $\cdot$ T. Vogt \\ The relative age effect in German 11- to 18-year-old male and female swimmers}

\begin{abstract}
Relatively older athletes have a greater probability of being selected and subsequently exposed to a higher level of coaching, training and other talent-promoting factors. Grouping by chronological age is, therefore, considered to be one of the weaknesses in talent identification. A large number of studies have confirmed the prevalence of the relative age effect (RAE) across various sports, including swimming. This investigation aims to quantify the prevalence, magnitude and transient pattern of the RAE according to sex and events across German swimmers. The RAE was examined top-100 ranked swimmers (2004-2013) according to birth month, of three cohorts (born 1993-1995; $n=3630$ ) for the age groups 11-18. The $X^{2}$ tests and Cramer's V estimated effect sizes; odd's ratios and confidence intervals calculated relative discrepancies between the quartiles. The RAE is significantly present over all events for female swimmers until 13-15 and for males until 16-18 years of age. Effect sizes were moderate until $12 / 13$ years of age for females and $14 / 15$ years of age for males. No inverted effects were visible. Compared to previous reports on Australian as well as Portuguese cohorts, the RAE was prevalent over a longer time period. Therefore, the impact of negative outcomes from RAE appears to be greater among German age group swimmers.
\end{abstract}

Keywords

Long-term athlete development · Talent identification - Youth sport - Children . Athletic performance

strokes, there is a delayed effect in the males with the $400 \mathrm{~m}$ Freestyle. For females, the effects are delayed in $200 \mathrm{~m}$ Individual Medley as well as $100 \mathrm{~m}$ Fly. It can be assumed that differences in the pattern of birth quartiles in our cohort are associated with processes within the swimming system.

The present study's findings are in line with previous investigations in swimming. The magnitude was higher for the German cohort, than the Australian 


\section{Main Article}

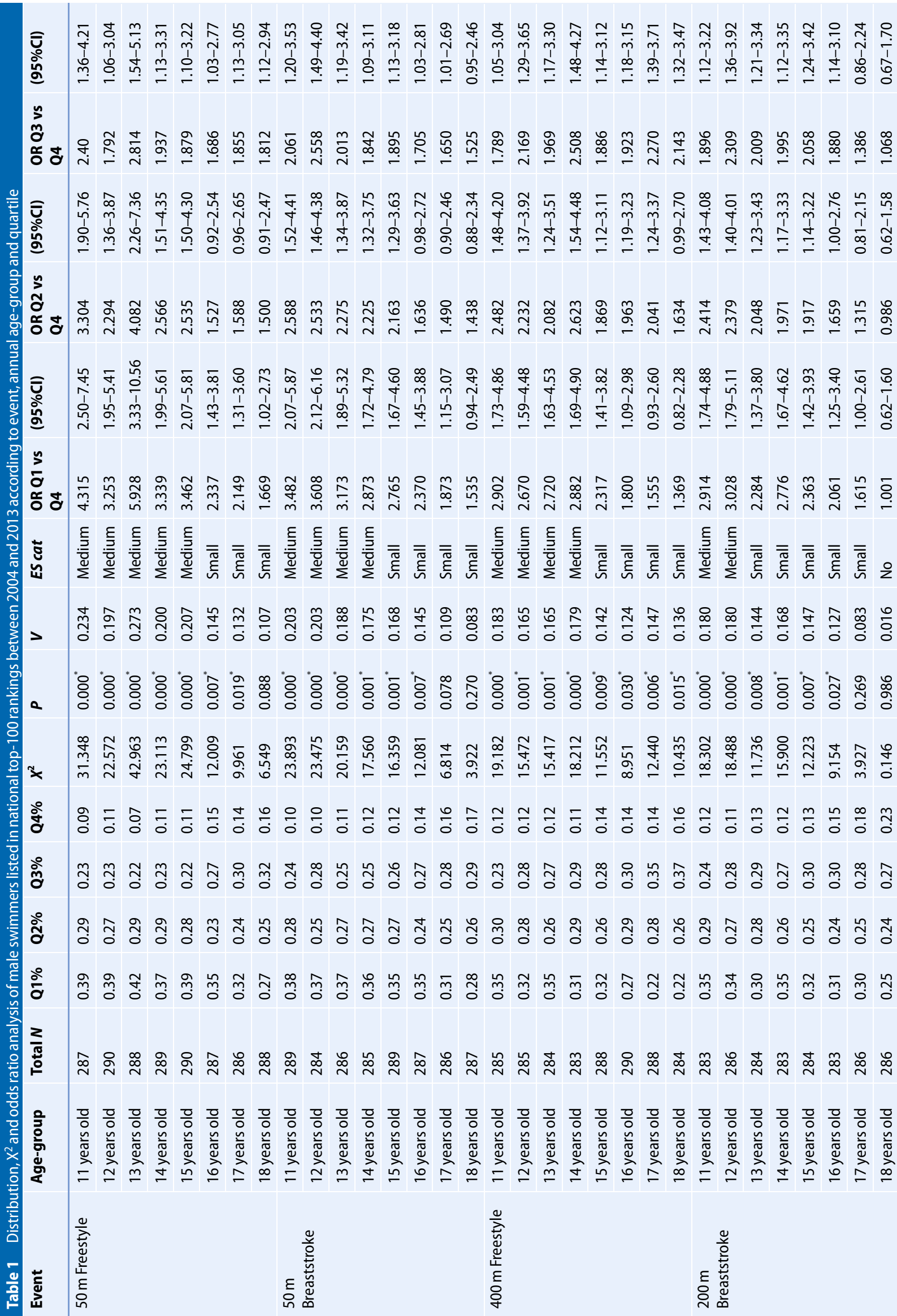




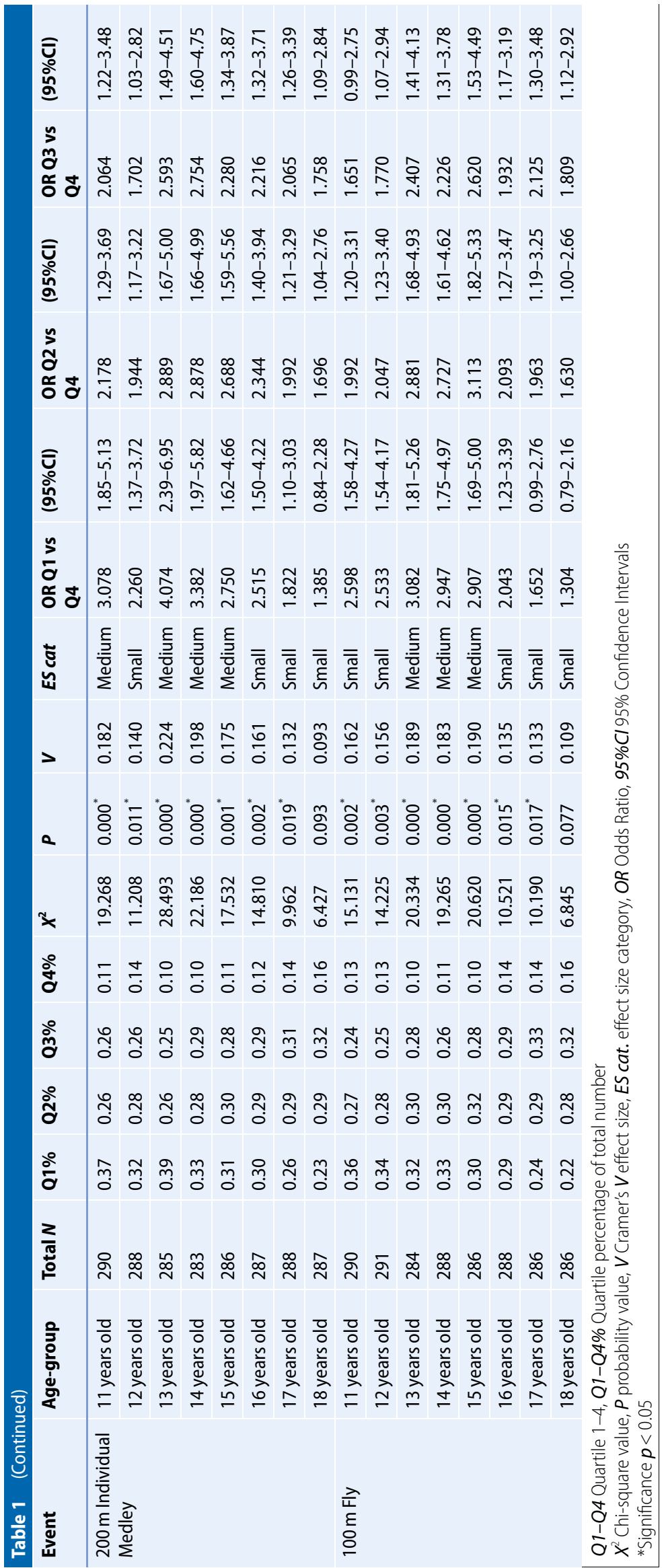

and Portuguese. Cobley et al. (2017) investigated a cohort of participants in Australian Age Swimming Championships between 12 and 18 years of age $(n=6.014)$. They found RAE in male swimmers $12-15$ and female swimmers 12-14 years of age. This effect disappeared earlier in their study compared to the present study's German cohort. Furthermore, Cobley et al. reported the effect to invert a year later among their Australian swimmers, whereas the present findings revealed no inversion until 18 years of age among German swimmers. In another study, Costa, Marques, Louro, Ferreira, and Marinho (2013) investigated a Portuguese cohort of top-50 ranked athletes between 12 and 18 years of age $(n=7.813)$. The disproportionately high distribution of relatively older swimmers was consistent for male swimmers from 12-15 years of age. In contrast to our findings the effect for female swimmers was only present at age 12 .

Taking into account research in longterm athlete development, it is well documented that the younger the athlete and the further away from peak performance, the more uncertainty of subsequent international success may be expected (Allen, Vandenbogaerde, \& Hopkins, 2014; Costa, Marinho, Bragada, Silva, \& Barbosa, 2011). There is also evidence that only one third of the 11year-old high-performance athletes still appear in the system at 18 years of age (Staub, Zinner, Stallman \& Vogt, 2020b), whereas early entry age was correlated negatively to success among 18 year old swimmers (Staub et al., 2020a). One mechanism that is considered to be sensitive to errors in that terms is organized talent selection. Analyzing different levels of performance as well as comparisons of the past decades provide indications for an influence of selection pressure and its impact on the RAE (Cobley et al., 2009; Cobley et al., 2008; Costa et al., 2012; Hancock et al., 2013; Schorer et al., 2009; Till et al., 2010).

In swimming, talent selection already takes place at the club level, focusing primarily on competition results at a young age, as well as regional championships also use qualification times. Further- 


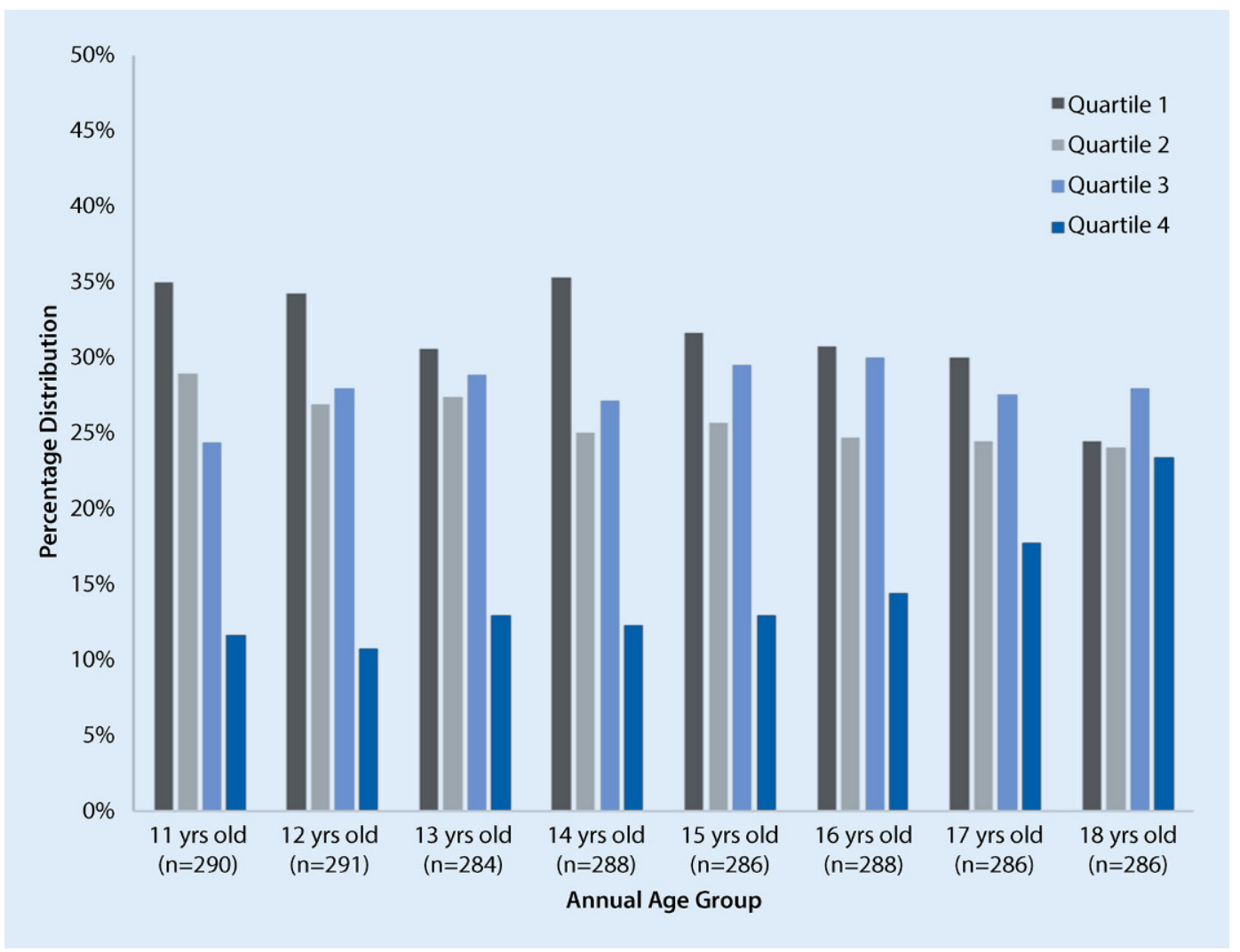

Fig. $2<$ Distribution of male swimmers listed in national top-100 rankings in $200 \mathrm{~m}$ Individual Medley (I.M.) between 2004 and 2013 according to agegroup and quartile. yrs years more, times and space in public swimming pools are at a premium so that local clubs are often assigned pool space in accordance to the performance level of their respective swimmers. With competition times referring to the level of technique as well as the physic of an athlete, this consequently leads to a RAE in connection to the maturation-selection hypothesis. Similar prevalence and magnitude were found in other sports with comparable technical and physical demands (Baker et al., 2014; Edgar \& O’Donoghue, 2005; Romann \& Cobley, 2015). Further indicating such a connection, the RAE revealed its greatest impact in those years associated with growth and maturation, both in the present study's cohort as well as in the Australian cohort. It seems reasonable to suggest that the RAE appears earlier among females, since their maturation may proceed earlier (Jenkins \& Reaburn, 2000). In the Portuguese cohort, however, the RAE was only found for male athletes.

These supposable minor differences which emerge from previous research and the present study's findings may indicate a varying influence of culturally deter- mined selection processes between countries. Moreover, differences between different sports and countries are also reflected in the organizational framework. For example, the selection pressure depends to a certain extent on the number of swimming pools available to a certain club or compared per capita within a country. This has yet to be explored.

The appreciation of a sport in the cults of a country, on the one hand, and, on the other hand, the financial incentives of some specific sports compared to others, may be considered relevant here. In this context, the choices of an athlete who has been deselected shall also be taken into account. In German soccer, positive effects of a nonselection on a collective level have been identified (Güllich, 2014). However, considering the differentiated league system, one explanation could be that nonselected athletes do not necessarily retire from the sport. Whether this is the case in swimming is unknown and remains to be elucidated. It can, however, be assumed that athletes who have been deselected from talent promotion programs have rather limited possibilities to find motivating infrastructure, if not even coaching personnel, to follow their career on a lower performance level. In countries with more pool space per inhabitant, this could possibly be different.

Another line of thoughts with respect to the present study's findings is taking a possible positive outcome into account; thus, younger swim athletes might benefit from greater competitions with their older counterparts (Gibbs et al., 2012). In this regard, differences in maturation of physical and psychological factors may even increase the gap between early born, early mature and late born, as well as late mature children (BaxterJones, 1995; Cobley et al., 2008; Malina, 2010; Vaeyens, Philippaerts, \& Malina, 2005), which makes it virtually impossible for the younger athletes to be selected. A recent study of the RAE in connection to maturation parameters in football revealed that teams with the same year of birth do not differ in these terms (Skorski, Skorski, Faude, Hammes, \& Meyer, 2016). This raises the question whether the 'underdog effect' exists in reality at all, or if the percentage of late born chil- 


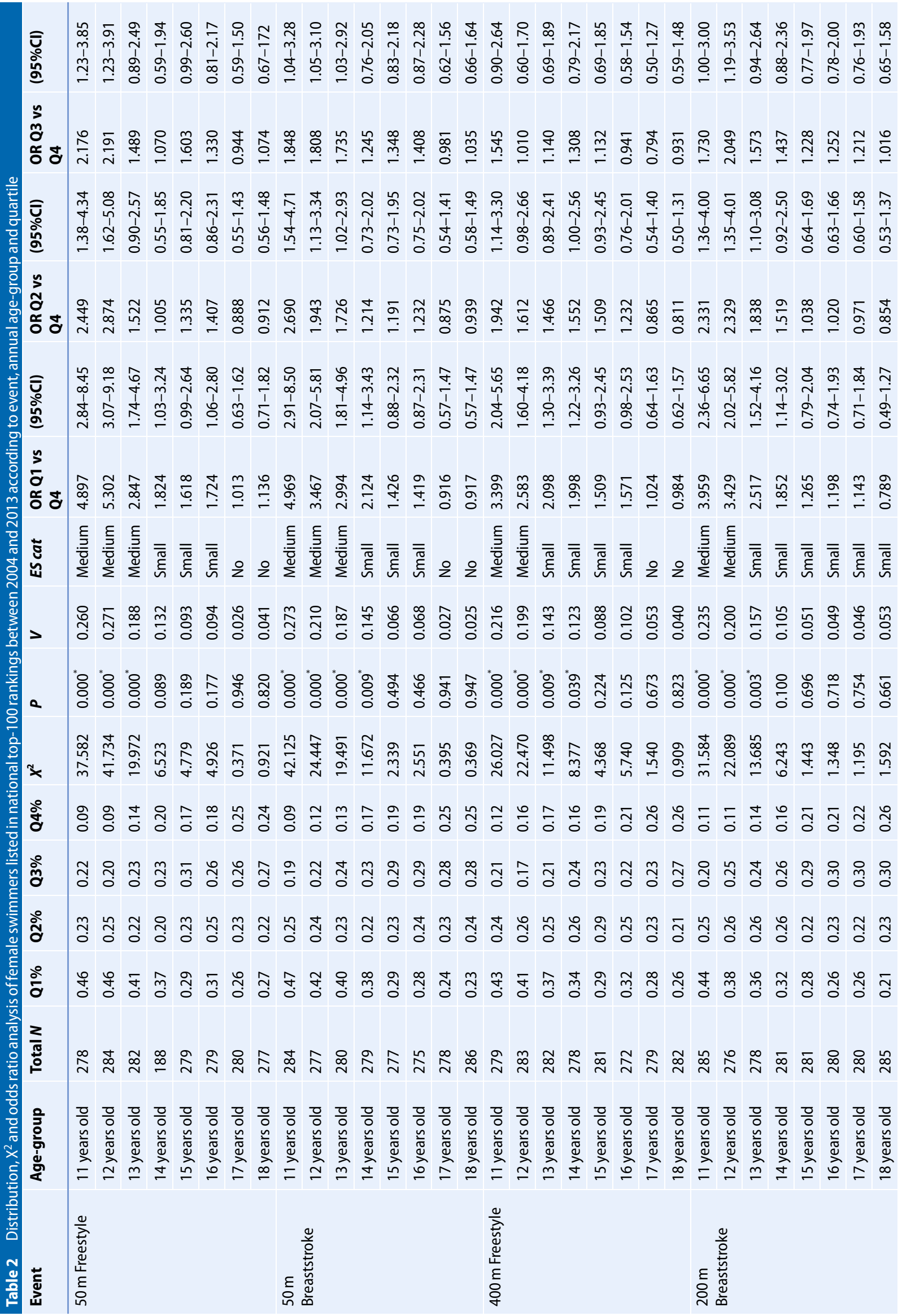




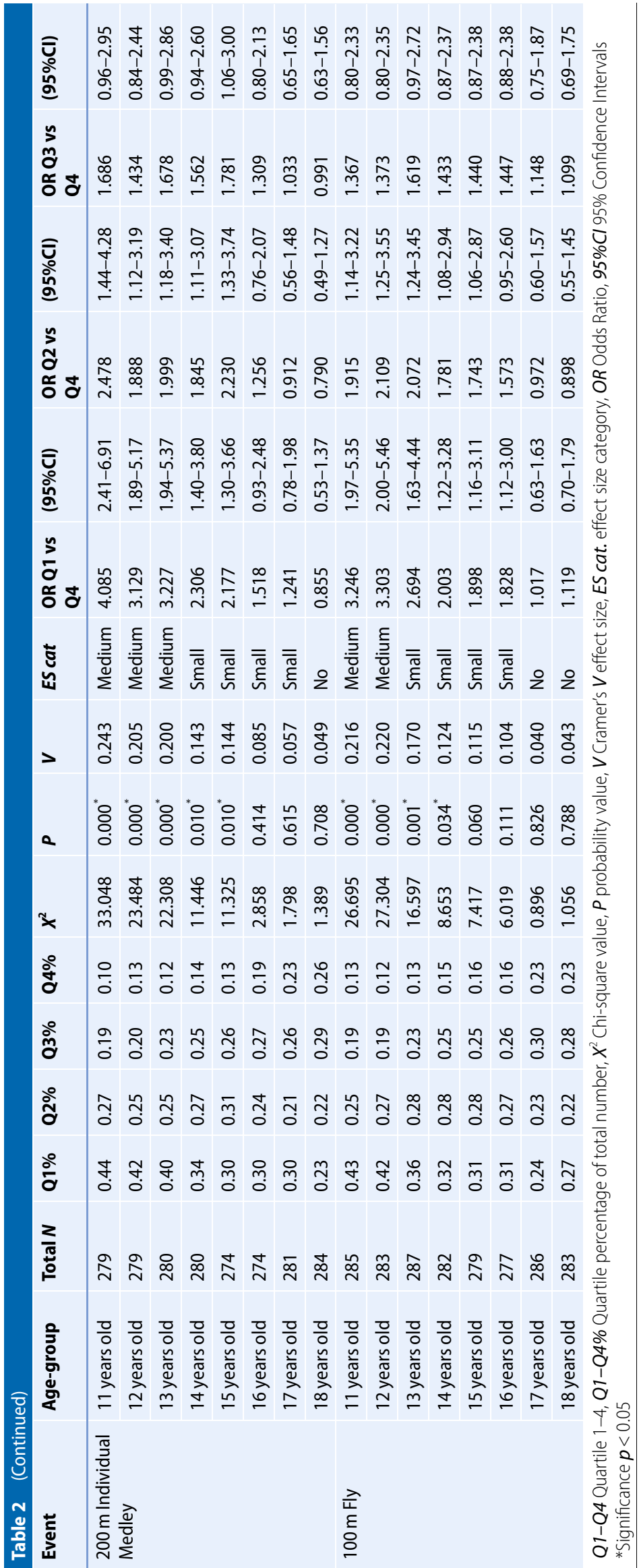

dren in a given age-group is just in terms of maturation above average.

Further consideration of transient performance and participation in athlete development systems and talent selection processes is needed. This may include revising the emphasis of sport programs according to developmental stages and delaying forms of athlete selection to improve validity. While to date, decisions are primarily made by coaches and parents (Wattie \& Baker, 2017), better information and education are necessary. Another possibility may be a quota system or intense support of those in the final quartiles (Larsen \& Alfermann, 2017).

The present study is still only observational. More insights on the connection of RAE to maturation as well as potential influence of geographical heritage in connection to pressure of talent selection are of further interest (Sherar et al., 2007) and may be investigated by future research.

\section{Conclusions}

This investigation provides new data contributing to the research on the relative age effect (RAE). In addition, it contributes knowledge about female sports, which are not yet well reported (Cobley et al., 2009). The RAE is prevalent in the cohort of German age-group swimmers for males and females across all events. The magnitude of the RAE decreases in the older age-groups, but no inverted effect was visible. Performance advantages associated with relative age (and thereby likely growth and maturation) are still prevalent in swimming.

\section{Corresponding address}

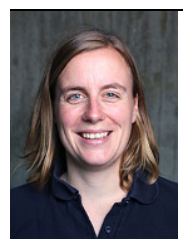

Ilka Staub

Institute of Professional Sport Education and Sport Qualifications, German Sport University Cologne Am Sportpark Müngersdorf 6, 50933 Cologne, Germany i.staub@dshs-koeln.de

Acknowledgements. The present research was supported by Deutscher Schwimmverband e. V. (DSV). The authors wish to express their sincere gratitude to 
Stefan Laux and Jonas Breuer assisting during data collection and preparation.

Funding. Open Access funding enabled and organized by Projekt DEAL.

\section{Compliance with ethical guidelines}

Conflict of interest. I. Staub, R.K. Stallman and T. Vogt declare that they have no competing interests.

For this article no studies with human participants or animals were performed by any of the authors. All studies performed were in accordance with the ethical standards indicated in each case.

Open Access. This article is licensed under a Creative Commons Attribution 4.0 International License, which permits use, sharing, adaptation, distribution and reproduction in any medium or format, as long as you give appropriate credit to the original author(s) and the source, provide a link to the Creative Commons licence, and indicate if changes were made. The images or other third party material in this article are included in the article's Creative Commons licence, unless indicated otherwise in a credit line to the material. If material is not included in the article's Creative Commons licence and your intended use is not permitted by statutory regulation or exceeds the permitted use, you will need to obtain permission directly from the copyright holder. To view a copy of this licence, visit http://creativecommons.org/licenses/by/4.0/.

\section{References}

Albuquerque, M., Tavares, V., Lage, G., De Paula, J., Da Costa, I., \& Malloy-Diniz, L. (2013). Relative age effectin olympicjudoathletes: aweight category analysis. Science \& Sports, 28(3), e59-e61.

Albuquerque, M. R., Lage, G. M., da Costa, V. T., Ferreira, R.M., Penna, E.M., de Albuquerque Moraes, L. C. C., etal. (2012). Relative age effectin olympic taekwondo athletes. Perceptual and motor skills, 114(2), 461-468.

Allen, S. V., Vandenbogaerde, T. J., \& Hopkins, W.G. (2014). Career performance trajectories of Olympic swimmers: benchmarks for talent development. European Journal of Sport Science, 14(7), 643-651.

Baker, J., \& Horton, S. (2004). A review of primary and secondary influences on sport expertise. High ability studies, 15(2), 211-228.

Baker, J., \& Logan, A.J. (2007). Developmental contexts and sporting success: birth date and birthplace effects in national hockey league draftees 2000-2005. British journal of sports medicine, 41(8), 515-517.

Baker, J., Cobley, S., Montelpare, W. J., Wattie, N., \& Faught, B.E. (2010). Exploring proposed mechanisms of the relative age effect in Canadian minor hockey. International Journal of Sport Psychology, 41(2), 148-159.

Baker, J., Janning, C., Wong, H., Cobley, S., \& Schorer, J. (2014). Variations in relative age effects in individual sports: skiing, figure skating and gymnastics. European Journal of Sport Science, 14(suppl1), S183-S190.

Barnsley, R.H., Thompson, A., \& Legault, P. (1992). Family planning: football style. The relative age effect in football. International review for the sociology of sport, 27(1),77-87.

Baxter-Jones, A. D. (1995). Growth and development of young athletes. Should competition levels be age related? Sports medicine, 20(2), 59-64.

Baxter-Jones, A., Helms, P., Maffulli, N., Baines-Preece, J., \& Preece, M. (1995). Growth and development of male gymnasts, swimmers, soccer and tennis players: a longitudinal study. Annals of human biology, 22(5), 381-394.

Cobley, S., Abbott, S., Dogramaci, S., Kable, A., Salter, J., Hintermann, M., et al. (2017). Transient relative age effects across annual age groups in nationa level Australian swimming. Journal of science and medicine in sport, 21(8), 839-845.

Cobley, S., Baker, J., Wattie, N., \& McKenna, J. (2009). Annual age-grouping and athlete development: a meta-analytical review of relative age effects in sport. Sports Med, 39(3), 235-256.

Cobley, S. P., Schorer, J., \& Baker, J. (2008). Relative age effects in professional German soccer: a historical analysis. Journal of sports sciences, 26(14), 1531-1538.

Costa, A. M., Marques, M. C., Louro, H., Ferreira, S. S., \& Marinho, D. (2013). The relative age effect among elite youth competitive swimmers. European journal of sport science, 13(5), 437-444.

Costa, I. T. D., Albuquerque, R. M., \& Garganta, J. (2012). Relative age effect in Brazilian soccer players: a historical analysis. International Journal of Performance Analysis in Sport, 12(3), 563-570.

Costa, M.J., Marinho, D., Bragada, J., Silva, A.J., \& Barbosa, T.M. (2011). Stability of elite freestyle performance from childhood to adulthood. Journal of sports sciences, 29(11), 1183-1189.

Cramér, H. (1999). Mathematical methods of statistics. Vol. 9. Princeton, New Yersey: Princeton University Press.

Côté, J., Macdonald, D. J., Baker, J., \& Abernethy, B. (2006). When "where" is more important than "when": birthplace and birthdate effects on the achievement of sporting expertise. Journal of sports sciences, 24(10), 1065-1073.

Daniel, T., \& Janssen, C. (1987). More on the relative age effect. Canadian Association for Health, Physical Education, and Recreation, 53, 21-24.

Delorme, N., Boiché, J., \& Raspaud, M. (2010). Relative age effect in elite sports: methodological bias or real discrimination? European Journal of Sport Science, 10(2), 91-96.

Edgar, S., \& O'Donoghue, P. (2005). Season of birth distribution of elite tennis players. Journal of sports sciences, 23(10), 1013-1020.

Ferreira, R. M., Coelho, E. F., de Morais, A. V., Werneck, F.Z., Tucher, G., \& Rocha Lisboa, A. L. (2017). The relative age effect in olympic swimmers. Revista Portuguesa de Ciências do Desporto, $105(17$ (S2.A)), 104-114.

Furley, P., \& Memmert, D. (2016). Coaches' implicit associations between size and giftedness: implications for the relative age effect. J Sports Sci, 34(5), 459-466.

Gibbs, B. G., Jarvis, J. A., \& Dufur, M. J. (2012). The rise of the underdog? The relative age effect reversal among Canadian-born NHL hockey players: A reply to Nolan and Howell. International Review for the Sociology of Sport, 47(5), 644-649.

Güllich, A. (2014). Selection, de-selection and progression in German football talent promotion. European journal of sport science, 14(06), 530-537.

Hancock, D. J., Starkes, J. L., \& Ste-Marie, D. M. (2015). The relative age effect in female gymnastics: a flipflop phenomenon
Hancock, D. J., Ste-Marie, D. M., \& Young, B. W. (2013). Coach selections and the relative age effect in male youth ice hockey. Research quarterly for exercise and sport, 84(1), 126-130.

Helsen, W. (2018). The relative age effect in youth and elite sport: did 20 years of research make any difference? Relative Age Effects: An International Conference. Windsor: University of Windsor.

Jenkins, D., \& Reaburn, P. (2000). Changes to the body during childhood. In D. Jenkins \& P. Reaburn (Eds.), Guiding the young athlete: all you need to know (pp. 1-5). St. Leonards: Allen \& Unwin.

Larsen, C. H., \& Alfermann, D. (2017). Understanding dropout in the athlete development process. In J. Baker, S. Cobley, J. Schorer, \& N. Wattie (Eds.), Routledge Handbook of Talent Identification and Development in Sport (pp. 325-335). New York, NY: Routledge.

Lemez, S., Baker, J., Horton, S., Wattie, N., \& Weir, P. (2014). Examining the relationship between relative age, competition level, and dropout rates in male youth ice-hockey players. Scand J Med Sci Sports, 24(6), 935-942.

Malina, R. M. (2010). Early sport specialization: roots, effectiveness, risks. Current Sports Medicine Reports, 9, 364-371.

Musch, J., \& Grodin, S. (2001). Unequal competition as an impediment to personal development: a review of the relative age effect in sport. Developmental Review, 21(2), 147-167.

Pearson, D., Naughton, G. A., \& Torode, M. (2006). Predictability of physiological testing and the role of maturation in talent identification for adolescent team sports. Journal of science and medicine in sport, 9(4), 277-287.

Raschner, C., Müller, L., \& Hildebrandt, C. (2012). The role of a relative age effect in the first winter Youth Olympic Games in 2012. Br J Sports Med, 46(15), 1038-1043.

Romann, M., \& Cobley, S. (2015). Relative age effects in athletic sprinting and corrective adjustments as a solution for their removal. PLoS One, 10(4), e122988.

Schorer, J., Cobley, S., Büsch, D., Bräutigam, H., \& Baker, J. (2009). Influences of competition level, gender, player nationality, career stage and playing position on relative age effects. Scandinavian journal of medicine \& science in sports, 19(5), 720-730.

Sherar, L. B., Baxter-Jones, A.D., Faulkner, R.A., \& Russell, K.W. (2007). Do physical maturity and birth date predict talent in male youth ice hockey players? Journal of sports sciences, 25(8), 879-886.

Skorski, S., Skorski, S., Faude, O., Hammes, D., \& Meyer, T. (2016). The relative age effect in elite German youth soccer: implications for a successful career. International journal of sports physiology and performance, 11(3), 370-376.

Stanaway, K. B., \&Hines, T. M. (1995). Lack of a season of birth effectamong American athletes. Perceptual and Motor Skills, 81(3), 952-954.

Statistisches Bundesamt (2019). Statistics of birth. https://www.destatis.de/DE/Home/_ inhalt.html $(2019,07.02 .2019)$.

Staub, I., Zinner, C., Bieder, A., \& Vogt, T. (2020a). Withinsport specialisation and entry age as predictors of success among age group swimmers. European Journal of Sport Science. https://doi. org/10.1080/17461391.2019.1702107.

Staub, I., Zinner, C., Stallman, R. K., \& Vogt, T. (2020b). The consistency of performance among age group swimmers over 8 consecutive years. 


\section{Main Article}

German Journal of Exercise and Sport Research, 50(1), 123-129.

Till, K., Cobley, S., Wattie, N., O'hara, J., Cooke, C., \& Chapman, C. (2010). The prevalence, influential factors and mechanisms of relative age effects in UK Rugby League. Scandinavian journal of medicine \& science in sports, 20(2), 320-329.

Vaeyens, R., Philippaerts, R. M., \& Malina, R. M. (2005).

The relative age effect in soccer: a match-related perspective. Journal of sports sciences, 23(7), 747-756.

Wattie, N., \& Baker, J. (2017). Why conceptualizations of talent matter. In J. Baker, S. Cobley, J. Schorer \& N. Wattie (Eds.), Routledge handbook of talent identification and development in sport (pp.69-79). New York: Routledge.

Wattie, N., Schorer, J., \& Baker, J. (2015). The relative age effect in sport: a developmental systems model. Sports Medicine, 45(1), 83-94.

Wattie, N., Tietjens, M., Cobley, S., Schorer, J., Baker, J., \& Kurz, D. (2014). Relative age-related participation and dropout trends in German youth sports clubs. European journal of sport science, 14(suppl1), S213-\$220. 